QUADERNS DE FILOSOFIA VOL. V NÚM. I (20I 8): 29-46

eISSN: 234I-3042 DOI: IO.7203/QFIA.5.I.IIO63

JaIME LLORENTE CARDO

IES Campo de Calatrava, Ciudad Real

\title{
Habitar la finitud: el primer movimiento de la existencia humana como asentamiento residencial en el pensamiento fenomenológico de Jan Patočka
}

To dwell in finitude. The first movement of human existence as residential settlement in Jan Patočka's phenomenological thought

Resumen: El presente estudio se centra en la interpretación del primero de los tres movimientos de la existencia humana postulados por el fenomenólogo checo Jan Patocka, como un procedimiento orientado a ocultar la originaria alteridad del Ser y, consecuentemente, a favorecer el habitar humano en el mundo. La propia estructura de nuestra percepción y nuestra relación original con los otros formarían parte de ese mecanismo de inserción residencial que caracteriza al movimiento de "anclaje" o "enraizamiento".

Abstract: The present work focuses on the interpretation of the first of the three movements of human existence postulated by the Czech phenomenologist Jan Patocka, as a procedure tending towards the concealing of the original alterity of Being and, in consequence, to favour human dwelling in the world. The structure of our perception itself and our original relation with the others would form part of that residential insertion that characterizes the movement of "anchorage" or "rooting".

Palabras clave: Patocka, habitar, movimiento de la existencia, enraizamiento. Keywords: Patocka, dwelling, movement of existence, rooting. 


\section{INTRODUCCIÓN}

$\mathrm{T}$ RAS LA INICIAL NOTORIEDAD derivada de su papel como portavoz del movimiento cívico Carta 77 y de las luctuosas circunstancias que como consecuencia de su compromiso político rodearon su fallecimiento, la figura del fenomenólogo checo Jan Patočka ha comenzado a ser conocida en los últimos años a través del examen de las tesis estrictamente fenomenológicas contenidas en su fragmentario legado teórico. Nos proponemos, mediante el presente estudio, contribuir a este examen hermenéutico y crítico mediante una interpretación relativa al sentido último que, a nuestro juicio, subyace tras la caracterización que Patočka ofrece acerca del primero de los — por él llamados_ "tres movimientos constitutivos de la existencia humana". Tales movimientos corresponden a otras tantas posibilidades fundamentales de la vida en el mundo y en cada uno de ellos se torna efectiva una de esas posibilidades. ${ }^{1}$ Desde esta perspectiva, Patočka caracteriza el primer movimiento original de nuestra existencia en los siguientes términos: "Hay, por tanto, tres movimientos fundamentales de la vida humana a los que corresponden tres necesidades y, en este sentido, tres posibilidades fundamentales de ella. En el primer movimiento nos relacionamos con lo que ya existe, con lo que hay en el mundo sin nuestro concurso, pero listo para nosotros; el ser aceptado es por ello el contenido íntegro de este movimiento, como un vivir a cubierto, bajo la protección de lo que ya preexistía" (2004, 82). ${ }^{2}$ Nuestra tesis inicial será que el "movimiento de aceptación" en virtud del cual el sujeto individual es acogido en el mundo estableciendo en él un anclaje radicado en el dominio de la totalidad abierta del ente, supone tácitamente una conjura de aquella alteridad inicial que el propio Patočka presiente cuando

\footnotetext{
${ }^{1}$ Patočka advierte, en este contexto, de que "Los movimientos de la vida no son determinaciones puramente antropológicas, ónticas. Tienen realmente una significación ontológica (en relación con el hundimiento en la neutralidad del ser). Movimiento de penetración en el 'mundo': Disposición, enraizamiento, aceptación. Privación - desgaste de sí: trabajo, dominación, lucha. Movimiento de salida fuera del 'mundo', de trascendencia hacia el mundo y hacia el ser" (I995, 135). Siempre teniendo en cuenta como apunta A. E. Garrido Maturano, el modo en el que Patočka comprende el "concepto de mundo"; una noción según la cual: "el mostrarse supone no sólo lo que se muestra y el sujeto al que se le muestra algo, sino el horizonte en el que se produce el encuentro de estos dos entes distintos. La manifestación no puede desarrollarse ni en el marco de un ente individual ni en el de la relación entre dos entes individuales considerados por sí mismos, sino que presupone algo así como un terreno común que esos entes puedan compartir. Precisamente el horizonte dentro del cual ese lugar se vuelve comprensible como medio común en el que puede producirse tal encuentro es el mundo. El mundo es el campo fenomenal o suelo en el que acontece toda manifestación" (Garrido Maturano 20 I4, 131).

${ }^{2}$ Como anota Patočka fragmentariamente: "movimiento de enraizamiento, hacia aquello que ya es, aquello que constituye siempre mi situación orientada hacia la aceptación, la acogida, el placer que puede llegar hasta el éxtasis" (I995, 158).
} 
habla en este contexto de adikía o "inadecuación" original entre el hombre y el mundo. ${ }^{3}$

Dicho más claramente: el movimiento gracias al cual el mundo deviene cálido espacio de hospitalidad, es decir, hogar para el individuo recién advenido a él, supone en realidad la inicial negación y ocultación (más o menos intencionada) de una extrañeza originaria hacia el "ente abierto e individuado" que precede radicalmente a todo anclaje en lo mundano. ${ }^{4}$ Inquietante extrañeza que por ello es temida y ha de ser cancelada, enmascarada para uno mismo, esto es, en definitiva, olvidada. La auténtica "necesidad" a la que correspondería este movimiento liminar del existir humano, sería, pues, la necesidad de olvido. La teoría patočkiana del movimiento de amarre original merced al cual el sujeto es recibido e introducido en el mundo, supondría precisamente, conforme a nuestra perspectiva hermenéutico-crítica, una larvada tentativa tendente a facturar un remedio filosófico capaz, si no de suprimir, sí al menos de lenificar y atemperar (hacer olvidar) una alteridad ontológica presentida acaso como originaria, como inderogable. Por lo demás, con esta pretensión, no estimamos buscar nada distinto a aquello a lo que el propio Patočka apunta cuando caracteriza esencialmente a la filosofía como "esfuerzo por abolir un olvido". 5

De este modo, la fenomenología "asubjetiva" de Patočka no solamente secundaría la perspectiva heideggeriana que sitúa la donación del Ser como evento originario previo a la subjetividad, sino que constituiría una teoría conforme a la cual la ipseidad jamás puede fenomenalizarse con independencia del don ontológico entregado por el mundo objetivo (en franca oposición a posturas fenomenológicas como las sostenidas por Michel Henry, para quien la vida trascendental puramente inmanente se auto-afecta patéticamente de forma radicalmente "acósmica" "in-exstática"). Ni tampoco le es dado hacerlo al margen del acontecimiento (Ereignis) del Ser que, sin asumir él mismo el estatuto de "objeto", sí acaece (ereignet) de modo externo a toda subjetividad

${ }^{3}$ Tal vez ahí radicaría el sentido de que, al decir patočkiano, el ideal de vida propio del movimiento de anclaje "es un ideal 'estético', el instante del disfrute, la inmediatez, la 'felicidad', aquello que intensifica el movimiento extático de la vida de forma inmediata y fortuita, sin esfuerzo ni ascesis [...]. El fin perseguido no es nada libre, nada que el hombre haya elegido él mismo, sino, al contrario, algo fascinante a lo cual él se abandona y se entrega en cuerpo y alma" (Ратос̌Ka I995, 111).

${ }^{4}$ De hecho, como indica Hubert Faes, "Le monde n'est apparu comme monde que quand les hommes ont justement cessé de n'y voir que le sol de leur enracinement, le fondement ou la communauté d'appartenance" (FAES 20I2, 34).

5 "En nuestra cándida e inmediata experiencia pasamos de largo y olvidamos aquello que la hace posible. El objeto de la filosofía queda olvidado en ella. Para nosotros, las cosas bastan en sí mismas, y no reflexionamos acerca de la manera en que se presentan y cómo esto es posible. Están aquí, sencillamente [...]. Así pues, la filosofía no es otra cosa que despertar del olvido a nuestro pensamiento, a nuestra alma y a nuestra vida espiritual entera" (РАTOČKA 2005, 33). 
particular. En Platón y Europa, Patočka se muestra explícito acerca de esta preeminencia reconocida al don ontológico sobre la mismidad subjetiva: "la subjetividad misma debe mostrarse como algo que aparece, como formando parte de una estructura más profunda, como una cierta posibilidad esbozada e indicada en esta estructura como una de sus partes componentes" (PATOČKa I983, 50). ${ }^{6}$ Con ello, Patočka asumiría no solo esa primacía de lo extra-subjetivo, anónimo y neutro a lo cual se refiere Emmanuel Levinas cuando contempla críticamente la "ontología" de Heidegger y aun toda la ontología tradicional, sino también - y aquí radica lo esencial de nuestra interpretación — la tesis heideggeriana fundamental que postula una ligazón originaria entre el propio "acontecer" del Ser y el acto de "habitar" (Wohnen) por parte del hombre. Entre el "es gibt" o "darse" constitutivo del Ereignis y la instauración de un firme asentamiento residencial (Aufenthalt) en virtud del cual el hombre mora en la vecindad de las cosas y es acogido en el seno del ente en su totalidad. Esta es, a nuestro juicio, la significación última que alienta tras afirmaciones como la siguiente: "el mundo y el mundo en torno humano muestran que el vasto mundo puede proporcionar un suelo para la actividad de sentido del hombre, al punto de poder convertirse en la tierra natal del hombre" (РАтос̌Ka 2004, 92). Trataremos, pues, en lo sucesivo, de dotar de consistencia a esta perspectiva mediante la consideración de las diversas descripciones fenomenológicas que Patočka lleva a cabo en referencia al primero de los movimientos de la existencia humana.

\section{El PROTO-MOVIMIENTO DE ANCLAJE: UNA ARMONÍA CONTRA LA EXTRAÑEZA ORIGINAL}

En sus célebres Ensayos heréticos sobre la filosofía de la historia, Patočka muestra ya decididamente sus bazas con respecto a la cuestión recién indicada, al caracterizar los tres movimientos fundamentales de la existencia humana

${ }^{6}$ Patočka aclara, además: "Esto no significa que sea posible un aparecer que no aparezca a nadie. Sin embargo, este alguien o algo no es ni su creador ni su portador. Aquello que porta, es la estructura, y esto o aquel a quien aparece aquello que aparece (el ente), es un momento y una parte integrante de esta estructura más fundamental" (I983, 50). En su notable monografía sobre Patočka L'ouverture du monde, Renaud Barbaras observa a este respecto lo siguiente: "Dire en effet que la subjectivité est un apparaissant, c'est reconnaître qu'elle fait partie d'un apparaître, ou plutôt d'une structure d'apparaître dont elle est un moment, une partie intégrante. Cela signifie deux choses: d'une part, que l'apparaître n'est pas porté par la subjectivité puisqu'il la rend au contraire possible comme surgissement de cet étant apparaissant singulier qu'est le vécu; d'autre part, que l'apparaître enveloppe la référence à la subjectivité comme une dimension qui lui est constitutive [...]. Le sujet vient donc recueillir et accomplir une manifestation qui est autonome et, pour ainsi dire, plus profonde que lui" (BARBARAS 20 I I, 206). 
como "movimiento de aceptación" (también llamado "de anclaje" o "de enraizamiento"), "movimiento de defensa" y "movimiento de verdad". El primero de ellos, que sirve de base a los dos restantes, da cuenta del hecho de que el sujeto individual recién advenido al mundo ha de ser acogido y alojado en su seno. La irrupción del hombre singular en el horizonte abierto del Ser presenta, pues, un carácter de adecuación, de aceptación recíproca o, como indica el propio Patočka, "de preparación y de ayuntamiento (harmonía) mutuos" $(\mathrm{I} 988,50) .^{7} \mathrm{La}$ inserción de la individualidad humana en la totalidad del ente no puede ser parangonada en modo alguno con el modo de adaptación puramente "mecánico" que asumen a tal respecto los elementos naturales o los objetos manufacturados. Un modo de ser definido por la indiferencia hacia "la infinidad del universo" y los "entes individuados" que lo pueblan o, como prefiere expresarlo el pensador checo, "ni indiferente ni no indiferente, sino simplemente carente de sentido para él" (Ibíd.). De modo inverso, el ingreso del sujeto humano en la totalidad de lo ontológicamente dado se halla regida por una radical no-indiferencia hacia ello; una no-indiferencia en cuyo trasfondo más profundo parece columbrarse la inquietante sombra de la alteridad radical. ${ }^{8}$

Nos encontramos ya aquí, en el comienzo absoluto marcado por el inicial proto-movimiento de la existencia (movimiento de "anclaje"), con el presentimiento de un originario hiato, de una prístina cesura ínsita en el gozne mismo que articula la supuesta armonía entre hombre y mundo. En efecto, el propio hecho de que Patočka hable explícitamente de "armonía recíproca" en referencia a esta consonancia original, muestra, de manera tácita e indirecta, que la nece-

\footnotetext{
7 Sobre la cuestión relativa a esta "armonía", Iván Ortega Rodríguez arriesga la siguiente hipótesis: "En el dinamismo dentro de la existencia (que más tarde es el movimiento de la existencia), hay dos momentos que juegan un papel importante en los análisis de Patočka. Son la armonía fundamental entre el hombre y el mundo y el distanciamiento respecto a lo dado, dos datos que encuentra continuamente en sus análisis. Apuntan a rasgos esenciales de la relación subjetividad-mundo y del movimiento de la existencia. Es más, creemos que la presencia persistente de estos datos es el origen de la teoría de los tres movimientos de la existencia" (OrTEgA RODRÍGUEZ 20I3A, 307).

${ }^{8}$ Tal vez esa alteridad es lo presentido cuando en “¿Qué es fenomenología?” Patočka interpreta el "irrumpir" del Dasein heideggeriano en la totalidad del ente como referencia a la "negatividad" encarnada en el "no ser": "Se trata, por tanto, del 'irrumpir' el ser que es 'el hombre' en el todo del ente (en el universo), en orden a que el todo del ente 'pueda romper' en lo que es y tal como es. El ente como tal necesita de este 'irrumpir' y 'romper en', que desde sí mismo no le puede advenir [...]. Pero esta irrupción solo puede a su vez producirse en virtud de una existencia que está en relación originaria no ya con el ente, sino con el ser. Relación con algo o hacia algo, que no es ningún ente, y que en este sentido no es; así, pues, una relación que desde el punto de vista del ente lo es hacia el no ser. Mas esta relación es el fundamento del aparecer de lo que aparece $[. .$.$] . Considerado desde el ente, comoquiera que no es ningún ente, ha de ser$ una nada" $(2004,273)$.
} 
sidad de "ar-monizar" (esto es, de "tornar uno y único") presupone ya la previa presencia de una disonancia o "dis-armonía" (una duplicidad polémica) más originaria que el acto de introducción y aceptación del sujeto en el horizonte mundano. Dicho de otro modo: si resulta inicialmente preceptivo "introducir", "acoger" o "anclar" al hombre en el mundo como postula Patočka, ello se debe a que proto-originalmente (con anterioridad a tal acto de inserción) se da una cesura entre lo humano y lo mundano más antigua que toda posible aceptación. Una fractura ontológica que tal aceptación o introducción precisamente presupone ya en cuanto tal y que el movimiento de anclaje se encarga de remediar. Si es necesario introducir al hombre en el contexto general del mundo, es porque se halla inicialmente "fuera" de él: en el marco de una "exterioridad" que redunda en inadecuación, en "des-ajuste" o a-dikía con respecto a la trama universal de lo dado. Esta inadaptación dis-armónica primigenia comparece, pues, en términos de signo que apunta hacia la presencia de una alteridad anterior a la acogida del individuo en el mundo. El propio Patočka intuye esa disonancia original cuando enfatiza el hecho de que al hombre la irrupción en el Todo del universo "Desde el principio le resulta no indiferente, 'siente' su extrańeza; sensible a la 'in-justicia', a la 'alta de propiedad' (adikia), requiere la 'justicia' (dikēe) y realmente la encuentra” (Ibid.).

Así pues, es el sentimiento de "extrañeza" — de alteridad— el que se halla en la raíz de toda necesidad de "anclaje" en la firmeza ontológica brindada por el mundo. Es la impresión original de a-dikia ("in-adec-uación", "in-justicia", des-a-juste") la que se muestra ahora como origen y causa de la voluntad de enraizamiento: de la demanda de díké o "ajuste" entre sujeto y mundo que alienta tras el proto-movimiento de aceptación. De ahí que, en contraposición a la gelidez propia de la alteridad y al carácter inhóspito ligado al desenraizamiento, Patočka se refiera habitualmente a la díké derivada del primer movimiento de la existencia mediante términos relativos a la calidez asociada a lo amigable y acogedor.' Así, en sus Lecciones sobre la corporeidad, el fenomenólogo checo indica que: "El ser humano es también, como el animal, un ser instintivamente sentiente y afectivo que se abre al mundo en la pasividad y la consonancia, respondiendo con un movimiento reflejo a los estímulos que recibe. En nuestro

9 "La adikía que experimenta [el ser humano] (la incursión, la irrupción) es reparada por los demás, que le reciben y hacen para él del mundo ese hogar cálido y acogedor en que se piensa al hablar del mantenimiento del fuego vital" (Ратос̌Ka 1988, 50). Asimismo, en El mundo natural y la fenomenología Patočka escribe explícitamente: "Antes de toda orientación, de todo comportamiento, de todo hacer, está siempre el anclaje, el enraizamiento, que tiene lugar en una dimensión de pasividad a la que uno está dejado [...]: el mundo entero puede ser un regazo materno, refugio cálido, cordial, sonriente, protector. O puede ser un frío cósmico, de helado y mortal aliento [...]. La posibilidad de la vida es la posibilidad de este calor, de esta sonrisa correspondida, de esta aceptación previa que nos pone a cubierto" (РАтос̌Ka 2004, 45-6). 
movimiento de anclaje o enraizamiento, que figura de comienzo a fin como base fundamental en la polifonía de la vida, hay igualmente una consonancia con el aspecto global del mundo, un impulso hacia el apego, el calor vital, la fusión, la dicha, lejos de lo extraño, del frío y de lo aversivo, impulso que se realiza en los movimientos cumplidos por nuestro cuerpo [...]. Por el aspecto de su ser que constituye el movimiento afectivo, el hombre se encuentra sumergido en el mundo, no como medio pragmático y práctico, sino como espacio omni-englobante de calor y de frío. Más precisamente, de calor o de frío vital" (РАтоČKa I995, 108-9).

La crucial alusión patočkiana al "impulso hacia el apego", a esa pulsión orientada hacia la adhesión y la vinculación al mundo, muestra, a nuestro juicio, el modo en el que el pensador checo trata larvadamente de restañar la herida originaria que acaba de presentir en la irrupción misma del fenómeno humano en el tejido del cosmos. Se trataría, en efecto, de postular una "correspondencia originaria" entre lo subjetivo y lo objetivo, entre el hombre y el mundo, que, aun sin ser plenamente aprehendida por la conciencia, antecede de modo absoluto a nuestra constitución y percepción de un mundo objetivo en general. De esta forma, puesto que cada acto individual de percepción u "objetivación" acontecería sobre el trasfondo de esta "adecuación" original y la presupondría necesariamente, lo verdaderamente originario sería tal "correspondencia”, y no ya la alteridad: la adikía o dis-armonía que inicialmente habíamos encontrado a través de la no-indiferencia con la que el sujeto humano recala en la apertura del mundo.

Así, en caso de que a la constitutiva tendencia intencional propia del sujeto le correspondiera originalmente un acto de conformidad y aceptación por parte del mundo objetivo, esta convergencia acontecería con radical prioridad a toda captación concreta de un "objeto" y, por tanto — que es lo pretendido en último término-, antes que toda posible experiencia de la alteridad. Esta aparecería, así, como instancia derivada de una identidad original. Como subsidiaria con respecto al primigenio acontecimiento del acuerdo armónico entre el movimiento de la intencionalidad subjetiva y el propio de la donación de los entes mundanos. Y con ello resultaría efectivamente neutralizada. Este es, conforme a nuestra interpretación, el sentido último que cabe intuir en el trasfondo de declaraciones como la formulada por Patočka al final de su ensayo Fenomenología y metafísica del movimiento: "Antes de toda objetivación, debe haber en el ente mismo una adhesión (Sich-Fügen) a nuestra intención, a nuestro impulso intencional, y es solamente sobre la base de este acuerdo que el mundo se da a nosotros también 'objetivamente' como algo intuido enfrente de nosotros. Esta concordancia no es nunca dada en la intuición y su objetivación [es invisible, no-objetiva e inaparente], pero cada intuición, cada 
objetivación, cada acto humano se cumple sobre su fundamento y es expresión suya" (РАтос̌Ka I995, 27). ${ }^{10}$

\section{LA PERCEPCIÓN COMO MECANISMO DE ENRAIZAMIENTO}

Así pues, "con el movimiento subjetivo, estamos sólidamente anclados en la realidad efectiva" (PaTočKa I995, 19), pero este acto de afianzamiento ha de venir ya prefigurado por el propio modo estructural en el que se constituye nuestra percepción común. Esto significa, según Patočka, que la estructura misma de la percepción se muestra ya como "anticipación" y "prolongamiento" de aquella función de asimilación que se verifica en el modo en que nuestros órganos sensoriales "colonizan" en cierto modo el inicialmente ignoto espacio del mundo objetivo, despojándolo así de su primera extrañeza. ${ }^{11} \mathrm{Y}$ es que recordémoslo- mencionar la función de "asimilación" en este contexto equivale a hablar tácitamente de "suspensión" o "neutralización" de una alteridad originaria. De este modo, mientras que la visión, la vista, aparece como una suerte de "don" o "dádiva" entregada por "la gracia de la luz del mundo" y que no precisa de esfuerzo ni de conflicto alguno, el tacto, el contacto táctil, "es para nosotros una manera de apoderarnos de las cosas" (РАтоČKA 2002, 61). ${ }^{12}$

${ }^{10}$ Resultan pertinentes al respecto las observaciones apuntadas por Edward F. Findlay en su estudio sobre Patočka "Caring for the soul in a postmodern age". En referencia al primer y fundamental movimiento de la existencia, aquel que actúa como "centro de la vida humana", Findlay escribe: "This is the movement in which humans simply accept their situation, are in harmony with the world, and anchor themselves in it by accepting it as given. It is, Patočka writes, the acceptance of the entire world as if it were a mother's lap -an instinctual, prereflective acceptance. In this movement we sink roots into our surroundings, and we accept our dependence on another for safety and warmth. It is an instinctive-affective movement that provides us with our center in life [...]. This movement reflects an acceptance of the cosmos without reflection; we are in home in it but it is necessarily characterized by a lack of self-understanding. It is also a situation in which humans do not exert control over their situation" (FIndLAY 2002, 44-5).

${ }^{11}$ En su ensayo sobre Patočka "Appartenance et enracinement: le premier mouvement de l'existence", Renaud Barbaras indica agudamente al respecto: "l'appropriation perceptive du monde doit alors être comprise comme un moyen de rétablir une continuité qui a été perdue. Ainsi [...] l'arrachement au monde que représente le passage de la vie à l'existence recouvre en réalité une tentative de réconciliation, une recherche de l'unité perdue [...]. De ce point de vue, le premier mouvement de l'existence apparaît comme une véritable médiation, accomplissant, c'est-à-dire radicalisant, sous la forme de la naissance du sujet, une séparation première en vue de la surmonter au plan phénoménologique" (BARBARAS 2007, 108).

${ }^{12} \mathrm{Y}$ ello, teniendo siempre en cuenta que la luminosidad del "mundo" constituye, en la fenomenología de Patočka, un evento que es necesario diferenciar nítidamente de los entes mundanos concretamente percibidos. En sus lecciones de mediados de los sesenta acerca de la fenomenología de Husserl, el filósofo checo se muestra taxativo al respecto: "El mundo ( $s \downarrow \Downarrow t)$, la luz (su凶tlo) a la cual yo veo cada cosa y cada actividad que tengo ante mí, cada pro-yecto, se 
En su ensayo El espacio y su problemática, Patočka caracteriza esta doble dimensión sensorial postulando que, mientras que el espacio visual se presenta como una periferia carente de núcleo, el espacio táctil comparece más bien como un núcleo sin periferia. Esto significa, trasladado e incardinado en contexto perceptivo, que el campo visual se ocupa de dar noticia del entorno sin incluir en él al sujeto que lo percibe, mientras que, al contrario, el campo kinestésico-táctil únicamente "da" los objetos que constituyen y pueblan nuestro entorno en la medida en que estos se encuentran en contacto con nosotros: con un sujeto percipiente en general. Pero —y aquí radica lo esencial— el auténtico y más profundo trasfondo de ese espacio kinestésico-táctil, es decir, la esencia de la relación entre la subjetividad percipiente y el mundo, reside en actuar como "espacio de apoyo", como "tierra que nos sostiene" en tanto que elemento firme y seguro por excelencia. Así es como, al decir de Patočka, el espacio kinestésico-táctil asume la investidura de fundamento y sostén de los movimientos efectuados por un cuerpo (nuestro cuerpo "perpendicular" a la extensión de la tierra) cuya disposición vertical remite simultáneamente a un espacio visual paralelo. Un espacio, este último, que siempre se muestra en el fondo como espacio celeste que adviene a nuestra percepción desde la infinita distancia abierta por la perspectiva: por el enfoque proyectivo vinculado a la ubicación de nuestro cuerpo propio en cada momento.

De esta forma, como ya apuntamos, la propia estructura de la percepción en sus campos sensoriales fundamentales (visual y kinestésico-táctil) muestra ahora una adecuación esencial. Una correspondencia subyacente a su aparente oposición y más decisiva que ella, cuya significación más profunda no es sino revelar esa "consonancia con el mundo" y ese "impulso hacia el apego" que Patočka sitúa en el núcleo mismo del original "movimiento de anclaje", "aceptación" o "enraizamiento". ${ }^{13}$ Un sentido último que se deja presentir en

eclipsa enteramente en la claridad que adquiere este proyecto. De modo análogo a como la luz pura ciega, la claridad del mundo desaparece en las cosas percibidas, hasta el punto de no ser aparentemente distinta de ellas. El mundo se retira de las cosas que aclara, se retira por el hecho mismo de aclararlas, de mostrarlas y hacerlas accesibles [...]. Nosotros no vemos, no vivimos inicialmente el mundo en tanto que mundo, sino solamente bajo las especies de las cosas y de los proyectos singulares en el mundo" (РАTOČKa I992, 14-5).

${ }^{13}$ A ello se refiere Ortega Rodríguez cuando escribe: "Patočka piensa que hay un estrato fundamental de la experiencia en el que hay un contacto, e incluso una armonía, entre lo subjetivo y lo objetivo. En su tesis de habilitación, por ejemplo, afirma que el primer nivel en la constitución del mundo es el de lo sensorial y la percepción. En la percepción hay dos momentos, la 'presentación' (prezentace) y la 'articulación' (artikulace) [...], en la percepción hay un contacto efectivo con lo no-subjetivo [...]. En la sensibilidad, hay un contacto vital entre dos seres diferentes; este contacto afirma, en virtud de su inmediatez, una indiferenciación entre lo subjetivo y lo objetivo que es simultáneamente negada por el mismo hecho de que hay un contacto [...]. Este contacto está también presente, pues, en la 'segunda fase' de nuestro autor. En Cuerpo, comunidad, len- 
declaraciones como la siguiente: "Ella [esta correspondencia] indicaría por lo demás que hay, en el fondo mismo de la vida, una aspiración a entrar en contacto con las cosas, a anclarnos en medio de ellas, a apegarnos sólidamente a su edificio, a incorporarnos e insertarnos en su ensamblaje ya acabado. Una tendencia a construir, un proyecto arquitectónico en el sentido más fundamental del término" (РАTOČKa 2002, 62). ${ }^{14}$ Contemplada desde este punto de vista, la postulada correspondencia entre lo óptico y lo kinestésico-táctil constituiría ya el germen primero de todo acto de construcción, la raíz última de toda posible arquitectura y, por tanto, el auténtico origen de todo habitar. Es ahora cuando el acto de ser interpelados por las cosas del mundo y de establecer contacto directo con ellas se revela como una estructura cuya esencia reside en el acto de construir, de edificar una morada susceptible de dispensarnos efectivo asentamiento residencial en medio de la totalidad de lo existente. La concordancia sensorial entre la visión y el tacto deviene, de este modo, cauce expresivo de la originaria pulsión constructora que late en el seno de cada espacio particular. Muestra y revela el impulso a aproximarse a lo dado, a vincularse al mundo, a "incorporarse a un distrito amigablemente abierto del ente" (РАтос̌KA 2002, 63) que procure al sujeto aislado el "apoyo y calor" derivados simultáneamente de la acogida en un "nosotros" y de la inserción residencial deparada por la arquitectura.

Así pues, la morada concreta, la construcción arquitectónica "material" no sería, observada desde esta perspectiva, sino como una hipóstasis: un correlato "objetivo" (u "objetivado") de esos dominios de lo visual y lo táctil que testimonian ya nuestra situación de arraigo, de enraizamiento, en el interior del horizonte mundano. Una consecuente extensión, por tanto, de la forma de constituirse nuestro campo perceptivo sensorial como región de tangencia y vecindad con el mundo; región en cuyo interior los elementos intramundanos pueden ya interpelarnos y ad-venir a nuestro encuentro. De ahí, lo consecuente que resulta, contemplada a esta luz, la fórmula de Patočka conforme a la cual: "El relacionarse se define por la interpelación y la interpelación es, a la vez, en-

guaje, mundo, por ejemplo, se afirma igualmente que el primer nivel de la existencia humana en el mundo es el de la sensibilidad; aquí, el ser humano está en armonía sensual con el mundo" (Ortega Rodríguez 20i3a, 307-8).

${ }^{14}$ En referencia al uso por parte de Patočka de estos y otros términos relativos a la "conjunción” y el "ayuntamiento" (al apego), Karel Novotný formula en su estudio La genèse d'une hérésie las siguientes observaciones hermenéuticas cuyo sentido suscribimos plenamente: "Le concept central ici est celui d' " ajointement ». Avant la phénoménalisation dans le champ d'apparition, c'est-a-dire l'avancée des phénomènes hors du fond du tout du monde dans la lumière de l'intuition, il y a un ajointement à nous-mêmes de ce qui n'apparait pas. Comme cet ajointement précède l'apparaître, il n'est pas lui-même donné phénoménalement. Il ne peut être constaté dans le vécu de façon réflexive, analytique; il doit donc être présupposé" (NovotnÝ 20 I 2, 63). 
raizamiento" (2002, 265). Entre estos "entes intramundanos" comparecen de modo privilegiado los otros: el prójimo, el otro sujeto. Y es que, desde la perspectiva patočkiana, la auténtica raíz del "habitar", de la inserción residencial del sujeto en el acogedor "seno materno" del que habla Findlay, se localiza en el "nosotros" intersubjetivo. ${ }^{15}$ No es casual, en este sentido, que el fenomenólogo checo postule sin ambages que lo que se muestra a través de la conjunción entre los campos perceptivos no es sino "el nosotros que nuestro contacto con las cosas se esfuerza por lograr y en el cual aspiramos a una reconciliación con una parte esencial o incluso con la totalidad del ente" (РАтоČKa 2002, 61).

Pero, a la vez, el morar deriva del acto de "construir" mediante el cual el enraizamiento en la tierra se consuma asimilando e integrando todo lo extraño. Suspendiendo la alteridad de lo inquietante, distante y adverso al modo en el que los homínidos del filme 2001: A Space Odissey de S. Kubrick conjuran progresivamente la desasosegante alteridad provocada por la presencia del monolito a base de "colonizar" su espacio mediante el contacto kinestésico-táctil favorecido por sus propios cuerpos. Aludiendo tácitamente a este acto esencial de neutralización de la alteridad propiciado por el "construir", Patočka caracteriza el habitar lo finito como resultado "de la suma de los esfuerzos personales para enraizarse en el mundo, para anudar con el todo del ente una sólida relación de amistad que integre también en su armonía aquello que es totalmente extraño, lejano, indómito, hasta incluso tal vez indominable, siniestro y hostil. Aquello que se aglomera continuamente en la periferia y retumba como una lejana tormenta en los confines del mundo" (РАтос̌Ka 2002, 63-4).

Es conjurando por asimilación esta amenazante tempestad de lo radicalmente otro como realmente se configura un domicilio ontológico que Patočka describiría como "cálido" y "acogedor" por contraposición a ese "frío cósmico de la periferia"16 del que precisamente el movimiento de enraizamiento y anclaje trata de huir. De ahí la seducción que las nociones de "construir" y de

${ }^{15}$ Por ello, Patočka asevera que: "Nuestra relación actual a la habitación se enraíza, al mismo título que la concepción sagrada, en el espacio originariamente personal, en sus tendencias y su dialéctica en la cual el movimiento parte del esto para dirigirse, a través de la pareja tú-yo, hacia un nosotros en el cual encuentra reposo" (2002, 66). A este respecto, resulta sugestivo atender nuevamente a las observaciones de Barbaras conforme a las cuales: "L'enracinement est donc d'abord ancrage parmi les autres, le centre est originairement humain [...]. L'enracinement est constitution d'une interiorité première qui n'est pas encore celle du sujet mais du " chez soi ", c'est-à-dire de «l'espace » humain ou affectif ouvert par l'accueil ou l'acceptation. Il s'agit, en un sens, d'une "intériorité extérieure ", car elle me relie aux autres et s'oppose à la pure extériorité du monde inhumain, inhospitalier" (BARBARAS 2007, 102).

${ }^{16}$ Periferia gélida que Patočka vincula casi inconscientemente a la alteridad absoluta al indicar, como de pasada, que la concepción mítica del espacio descubre realmente "la periferia última, universal, que trasciende todo lo singular, en tanto que lugar en el cual, cesando el ente usual y habitual, se abre la posibilidad de la alteridad total" $(2002,68)$. 
"habitar" ejercen sobre el espíritu humano en todas las épocas y de la cual dan cumplido testimonio las imágenes poéticas que secularmente glosan "la magia del construir, de las construcciones y de los espacios" (Ibíd.). La aproximación entre los entes, su convergencia recíproca, es, por otra parte, el acto esencial que genera el habitar y el hallarse el hombre "como en casa" en medio de la totalidad de lo existente. El propio espacio "físico" se muestra, bajo la mirada fenomenológica de Patočka, como el escenario dinámico de un drama. Como acontecimiento, como acto eventual que se inscribe en otra representación de más amplio aliento: el drama de un mundo en el cual los personajes (los entes concretos) se arraciman y coaligan entre sí con objeto de propiciar un espacio ontológico hogareńo y acogedor: "parte del drama del mundo en el cual los seres se encuentran, se acercan, se juntan recíprocamente a fin de crear ahí su estar en casa, siempre tan profundamente deseado y amado, por precario y provisorio que sea (Ратос̌Ka 2002, 75).

Ese carácter "deseado" y a la vez "provisional" que Patočka reconoce al habitar humano muestra ya de modo larvado que si el morar ha de ser favorecido y en cierto modo "construido" (primero por la propia estructura de nuestra percepción y después por la propia reunión de los elementos así percibidos), ello se debe a que no se da desde el comienzo: a que no es en absoluto algo dado originariamente. Al contrario: la instalación residencial propiciada por el "movimiento de anclaje" se muestra, más bien, como un producto final, esto es, como el resultado de una factura operada de modo conjunto por el movimiento de enlace entre los objetos intramundanos y por los "caracteres últimos" propios de la percepción. ${ }^{17} \mathrm{La}$ aceptación no constituye, pues, un don, sino realmente una conquista. El habitar no es un hecho ya dado, sino un remedio. De ahí su precariedad y su carácter de situación deseada: "Arrojándonos a las cosas, anclándonos en ellas, aprehendiendo y creando nuevas síntesis objetivas, nos aprehendemos, nos abrimos y nos modificamos a nosotros mismos. Tal es la curva del movimiento de nuestra existencia" (РАтос̌KA I995, 70).

${ }^{17}$ En referencia a estos "caracteres" y a su relación con el enraizamiento mundano, Patočka escribe iluminadoramente: "Estos caracteres últimos, tales como la tridimensionalidad originaria de lo visual, la no-homogeneidad originaria del espacio sensible, la necesidad de las kinestesias para la comprensión de los data pasivos, etc., no se presentan como elementos aislados. Son parte integrante de algo que podría llamarse el aparato de enraizamiento originario, por el cual el sujeto entra en relación con el mundo, se instala en el mundo y se orienta en él" $(2002,80)$. 


\section{LA MORAda COMO CONJURA DEL CAOS}

Si realmente, como acabamos de ver, la aceptación residencial en el mundo pasa por el "drama" en virtud del cual los seres se enlazan para propiciarla, y por la "magia del construir" que la lleva efectivamente a cabo, entonces ¿qué habría de suceder en caso de que estos dos subterfugios fuesen suspendidos y eliminados? En buena lógica, la desaparición de la tupida urdimbre facturada por la conjunción de los elementos mundanos al reunirse bajo el mandato de las estructuras perceptivas del sujeto habría de ocasionar la paralela evaporación del "habitar" humano. Del asentamiento que ella mis$\mathrm{ma}$ —al decir de Patočka— se encargaba de producir y salvaguardar. ¿̇Ocurre realmente esto en el pensamiento fenomenológico patočkiano? Oigamos al propio pensador checo: "Cuando esta trama continua se rompe se produce inmediatamente una desorientación, una inestabilidad, un aislamiento de la impresión acompañado de un sentimiento de vértigo, de vacío, de desarraigo. Perdemos pie, no hallamos nada a lo que aferrarnos, nada sobre lo cual apoyarnos" (2002, 266). Se muestra aquí claramente la alteridad que subyace al tejido ontológico tramado por la estructura de la percepción: la inhospitalidad carente de morada que esta - y con ella el movimiento original de anclaje- se esfuerzan en atemperar y mitigar. La residencia aparece ahora como la consumación de la original tendencia a la creación de un espacio propio por parte del hombre. ${ }^{18}$ Un mundo particular cristalizado en forma de elemento físico - la casa - que pone en evidencia a esta como "la proyección al exterior de una posibilidad originariamente humana, reivindicada desde el origen" (PATOČKa 2002, 274), es decir, como expresión o hipóstasis "objetiva" de una pulsión subjetiva originaria: la voluntad de exorcizar la alteridad primigenia con la cual se nos da de modo inicial el ser del mundo para poder finalmente instalarnos en él y habitarlo. Así, el máximo mecanismo de enraizamiento (la casa) atestigua a la vez, de forma tácita, la originariedad de la suprema experiencia de desenraizamiento y falta de morada (la prístina experiencia de la alteridad ontológica del mundo). ${ }^{19}$

${ }^{18}$ Espacio sin alteridad que Patočka describe como sigue: "El hombre es el primer ser en descubrir el mundo íntimo por la intermediación del espacio íntimo. Un espacio que no pertenece más que a él, que no solamente le pone en lugar seguro, sino en el interior del cual modela todo a su imagen y según sus necesidades. Un espacio en el cual, solamente entonces, él es en sentido propio, en el sentido fuerte del término" (2002, 273).

${ }^{19}$ Es por ello que Barbaras apunta al respecto: "Bref, par le premier mouvement d'enracinement, l'appartenance se fait séparation. En ce sens, l'enracinement est tout autant un déracinement: en nous donnant un centre au sein du monde, nous le faisons paraître, et en le faisant paraître, nous nous arrachons à la condition des autres étants" (BARBARAS 2007, 105). 
A esta luz, no resulta sorprendente que Patočka recurra a las imágenes del nido, la choza o la caverna primitiva a la hora de ilustrar los elementos propios de la "habitación primordial". La casa no constituiría sino la suprema y más acabada expresión de la tendencia humana a la edificación de un espacio propio, de un hogar habitable; tendencia igualmente contenida de modo virtual en el primer movimiento de anclaje. La morada se define esencialmente por su función de "abrigo" y "protección", no solo ni principalmente contra las inclemencias ambientales externas, sino, más originariamente, contra la extrańeza primigenia: contra la potencia disolutiva propia de lo caótico. Pero si el arraigo sedentario aparece históricamente como el ideal a lograr, ello ha de deberse a que su contrario (el desarraigo ligado a la alteridad) se intuye ya como situación originaria, dada con prioridad a toda tentativa de inserción residencial en el mundo. Patočka explicita este hecho al conceder que "la sedentariedad es, en el fondo, la realización de un sueño, de una intención ya propia del hombre errante y desarraigado" (2002, 274), es decir, del hombre tout court. Así pues, si realmente — como sucede también, según Patočka, en la ontología de Heidegger- "la tendencia al enraizamiento, a fundarse en el ser-con-los-otros, está dirigida contra la disposición en su carácter posible de extrañeza inhospitalaria (Unheimlichkeit)" (I995, 136), entonces el movimiento de anclaje se muestra como una acogida por parte del mundo natural y humano (el Mit-sein) orientada a que la intersubjetividad, la socialidad, contribuya decisivamente a la conjura de la alteridad que nos aliena originalmente del mundo. ${ }^{20}$ Destinada al efectivo logro de esa "unidad entre el hombre y el mundo a la cual aspiramos" (2002, 138).

En el "Suplemento" de 1970 a su primera obra, la tesis de habilitación El mundo natural como problema filosófico, Patočka vierte posiblemente su palabra definitiva acerca de la caracterización de la triple "polifonía de la existencia humana", así como de su relación con esa "unidad entre hombre y

${ }^{20}$ Una proximidad explícitamente postulada por Patočka cuando escribe: "el mundo natural es un mundo en que se ha de poder vivir, vivir en común, ser aceptado y acogido, recibir esa protección que permite luego asumir tareas concretas de defensa y lucha contra lo que nos amenaza en el entorno de las cosas y de los hombres [...]. Arraigo, acercamiento, renovación de los vínculos de protección, forman uno de sus movimientos circulares fundamentales" (2004, 153). Así pues, como señala Ilja Srubar en referencia a "la primera fase del movimiento de la existencia humana completamente soslayada por Heidegger": "Patočka nomme cette phase le mouvement de l'ancrage, et il désigne par là le procès d'insertion originaire du sujet dans son monde par la relation à d'autres. C'est un procès d'appatriement de l'homme dans le monde par sa socialité, par son acceptation par les autres, procès au cours duquel se développe la « structure originaire " primaire de mon monde. C'est la compréhension, ici mise au jour, de la signification fondamentale de la socialité pour l'accomplissement de l'existence qui distingue Patočka de Heidegger" (SRUbar I992, 93-4). 
mundo" a la que acabamos de aludir. ${ }^{21} \mathrm{Y}$ también en este retrospectivo escrito tardío, reaparece la intuición según la cual el enraizamiento propiciado por el "movimiento de aceptación" representa realmente una tentativa de conjura del caos originario. Una exterioridad "periférica", como vimos, cuyo carácter gélido es parcialmente ocultado y enmascarado por la acogida dispensada por los otros - por la proximidad del mundo humano- ${ }^{22}$ pero que parece subyacer permanentemente "bajo" o "tras" ese amparo protector otorgado por la percepción y por el prójimo: "En la microsociedad humana, en el acercamiento humano, el mundo, que en el fondo es el afuera, genera algo como una interioridad exterior, un espacio en el cual lo cubierto disimula esta figura y protege contra la preponderante fuerza del afuera. Pero, por supuesto, el escalofriante exterior no permanece por ello menos presente de modo indirecto, delatado por lo no-dicho, en el seno de la seguridad que da esta protección" (Ратос̌Ka 20i6, 230).

Así pues, el movimiento original de la existencia humana bascula esencialmente entre los dos polos opuestos del "afuera" y de la "interioridad" resguardada. ${ }^{23}$ Esta última es representada, además de por la hospitalidad del prójimo, por la firmeza y seguridad asociadas al elemento estable par excellence: la tierra. En consonancia con el carácter "asubjetivo" de su fenomenología, Patočka presenta la tierra como un poder genérico, indeterminado y supraindividual que ejerce su dominio sobre la existencia humana desde la proto-inserción de esta en el mundo derivada del "movimiento de anclaje". Este poder universal reina, pues, sobre el "movimiento de enraizamiento" original y, por extensión, sobre la totalidad de los movimientos particulares e incompletos merced a los cuales la vida se apodera de las cosas externas que precisa para subsistir. De este modo, el núcleo central con el que vinculamos las cosas no lo constituye nuestra propia ipseidad ("asubjetivismo"), sino que esta se relaciona fundamentalmente con "las cosas del mundo y ante todo con la 'cosa universal' (Hegel) que es

${ }^{21}$ En referencia simultánea a esta cuestión y a la mencionada obra, Iván Ortega apunta pertinentemente: "En su tesis de habilitación, El mundo natural como problema filosófico, de 1936, Patočka plantea que la solución al problema de la división entre el mundo de la vida y el mundo descrito por las ciencias naturales descansa en la común referencia a la subjetividad trascendental. De esta manera, nos encontramos en su exposición con el mundo y la subjetividad como polos básicos en torno a los cuales ha de pensarse un problema determinado, como en este caso, el de la unidad perdida del mundo humano" (Ortega Rodríguez 20г3 B, 251).

${ }^{22}$ En palabras de Novotný: "le corps (Körper) vivant ne devient corps propre humain, sujet du vécu, qu'à travers l'acceptation par d'autres humains. Le milieu de ce mouvement est l'affectivité, l'« é-motio-nalité ». Voilà le noyau de ce que Patočka appele «le premier mouvement de l'existence humaine " (NovotnÝ 20I 2, 76).

${ }^{23}$ Hasta tal punto que Patočka no vacila al afirmar que "la estructura 'en casa' / 'extraño' puede ser considerada como una de las dimensiones esenciales del mundo natural” (2016, 233). 
la tierra" (РАтос̌Ka 20 Iо, 234). ${ }^{24}$ Mediante esta relación "el movimiento de anclaje aparece como una auténtica salida fuera de la noche oscura, una venida a la luz del día" (20I6, 235), pero "siempre permanece presente en él algo que escapa a su dominio: un caos propio de este mundo, pero también ajeno a él. La organización de la vida en conjuntos cada vez más amplios oculta algo indomeñable que no es una simple imperfección de la organización, sino, más bien, una ausencia de lo esencial" $(2016,241) .{ }^{25} \mathrm{Tal}$ elemento indómito no es sino, como apuntábamos al comienzo, la originaria alteridad del Ser.

\section{Conclusión}

La tentativa emprendida por Patočka de suspender la primigenia alteridad del mundo mediante el arraigo propiciado por el proto-movimiento de anclaje, constituye acaso un intento de conducir a la fenomenología —-más allá de las pautas instituidas por su fundador- por la senda de la reconciliación entre lo objetivo y lo subjetivo. ${ }^{26}$ Una reconciliación que aparece y se torna efectiva en el acto del habitar humano en el seno de la totalidad del ente. El sentido último del "anclaje" primigenio apuntaría, pues, a restablecer (o simplemente "reconocer") el carácter constitutivo de la continuidad ontológica entre el existir del hombre y el ser del mundo. No es de extrańar, por tanto, el hecho de que — en el "Suplemento" de 1970— Patočka presente la irénica escena bíblica del jardín del Edén como "imagen perfecta del movimiento de anclaje" (2016, 243), del mismo modo que en los Ensayos heréticos hace lo propio en referencia a la familia patricia de la antigüedad romana contemplada

24 "El referente de nuestra corriente efectuadora [...] es un sustrato inmóvil y permanente: la Tierra. La inmovilidad de la tierra forma parte de la orientación original del mundo. La tierra es aquello en que se sostiene la acción orientada y autoorientada. No podemos actuar si no es sostenidos sobre este fundamento firme de la situación vital compartida. Pero la Tierra no es solo el suelo en que inexcusablemente arraiga nuestro actuar; es a la vez el soporte firme de todo. Todo lo que llamamos 'cosa' descansa sobre ella [...]. Al erguirnos, al dar un paso, en todo movimiento que hacemos, la Tierra está presupuesta; de ella nos viene la energía y la fatiga, el apoyo y el descanso. En su condición de soporte y referente de todas las relaciones, la Tierra aparece también como fuerza y poder [...]. 'Hijo de la Tierra' no es solo, en consecuencia, una metáfora poética, sino la comprensión de algo esencial a propósito del hombre" (РАTOČKA 2004, 33-5).

${ }^{25}$ Es esa carencia la que ocasiona que el existente experimente "que su fondo es 'inhóspito', que él 'no tiene residencia entre las cosas': experimenta lo ajeno, la alienidad del ente como tal, es decir, la alienidad de su ser" (РАтос̌Ka 2004, 275).

${ }^{26}$ Por ello Patočka observa oportunamente que: "la perspectiva sin duda más importante de todas las abiertas por esta filosofía [la de Husserl] es aquella que toma en consideración la unidad, el ayuntamiento recíproco y la interdependencia del hombre y del mundo, visto el hecho de que nos es imposible desde entonces pensar al hombre sin el mundo o al mundo sin el hombre" (1992, 224). 
como "el ejemplo que mejor ilustra la temporalidad del movimiento de aceptación” ( 1988,53$)$.

Así pues, si verdaderamente es necesario postular que, incluso con anterioridad a la eclosión efectiva de la consciencia, "somos ya adoptados, absorbidos previamente por la relación al mundo" (I995, 62), ${ }^{27}$ es decir, que "no hay ninguna situación en que el hombre no tenga mundo" $(2007,307),{ }^{28}$ ello obedece acaso al hecho de que únicamente el "mundo" — tanto el "humano" como el modelado por nuestra percepción- parece ofrecerse como bastión salvífico al cual aferrarse tras resultar expuesto a la originaria y glacial alteridad del "afuera". Contemplado desde esta perspectiva casi "soteriológica", el pensamiento fenomenológico de Patočka constituye acaso fundamentalmente un oportuno trasunto de ese mundo protector en el plano de la reflexión filosófica. Remedo que, lejos de suponer una vía alternativa a aquella a través de la cual ha discurrido el sentido propio de la tradición metafísica, secunda el rasgo esencial subyacente a esta, a saber: la larvada voluntad de suspender la alteridad del mundo en orden a favorecer el arraigo (el "anclaje") en él de la vida humana. La fenomenología de Patočka se muestra, pues, en analogía con la "ontología" heideggeriana, como un pensamiento de la reconciliación. Reconciliación entre lo "objetivo" y lo "subjetivo" mediante la superación y la supresión misma de tales categorías, pero sobre todo reconciliación entre el movimiento propio del existir humano y el movimiento cósmico a través del cual se despliegan el devenir del mundo y la temporalidad que lo acompaña. Una tentativa de armonización que, sin embargo, en el último confín de su itinerario, se topa tal vez nuevamente con esa misma negatividad ontológica que ya se hallaba en la raíz de su propio origen.

${ }^{27}$ Como indica Barbaras: "le rapport à soi (conscience) est déterminé par l'apparition, loin que cette apparition repose sur une conscience: plus profond que la conscience, il y a la force de faire apparaitre les choses" (20 I I, 270).

${ }^{28}$ Jean-Yves Lacoste observa, en un sentido muy próximo al apuntado aquí por Patočka y en nada casual referencia a Heidegger, lo siguiente: "Previo a toda toma de conciencia o acto consciente, el mundo ha establecido ya su soberanía sobre el Dasein. 'Abierto' al mundo, no dispone frente a él de ninguna protección [...]; de hecho, el Dasein no es más que puertas y ventanas. En este sentido, no hay ser-en-el-mundo que no se refleje en la conciencia" (LACOste 20 Io, 20). 


\section{BIBLIOGRAFÍA}

Barbaras, R. 2007, Le mouvement de l'existence. Études sur la phénoménologie de Jan Patočka, Chatou: Les Éditions de la Transparence.

Barbaras, R. 20 i i, L'ouverture du monde. Lecture de Jan Patočka, Chatou: Les Éditions de la Transparence.

FAes, H. 20 I 2, "Naturalité, artificialité, historicité du monde commun. Hannah Arendt et Jan Patočka, en Frogneux, N. (dir.), Jan Patočka: liberté, existence et monde commun, Argenteuil: Le Cercle Herméneutique.

Findlay, E. F. 2002, Caring for the soul in a postmodern age. Politics and Phenomenology in the Thought of Jan Patockka, Albany, NY: State University of New York Press.

Garrido Maturano, A. E. 20 i 4, "Los ojos del universo: la existencia como origen afectivo del sentido en el pensamiento de Jan Patočka”, Cuadernos salmantinos de filosofía, 41: 127-47.

Lacoste, J.-Y. 20 Io, Experiencia y absoluto, Salamanca: Sígueme.

Novotný, K. 2012, La genèse d'une hérésie. Monde, corps et histoire dans la pensée de Jan Patočka, París: Vrin.

Ortega Rodríguez, I. 20i3a, "Una línea de continuidad en el pensamiento fenomenológico de Jan Patočka”, Pensamiento, 69, 259: 301-13.

Ortega Rodríguez, I. 20 13 в, "Existencia humana, mundo y responsabilidad en la fenomenología de Jan Patočka, Investigaciones fenomenológicas, monográfico 4/I: 247-64.

PatočKa, J. I983, Platon et l'Europe, Lagrasse: Verdier.

PAтос̌Ka, J. I988, Ensayos heréticos sobre la filosofía de la historia, Barcelona: Península.

PatočKa, J. I992, Introduction à la phénoménologie de Husserl, Grenoble: Millon. PatočKa, J. 1995, Papiers phénoménologiques, Grenoble: Millon.

PatočKa, J. 2002, Qu'est-ce que la phénoménologie?, Grenoble: Millon.

PatočKa, J. 2004, El movimiento de la existencia humana, Madrid: Encuentro.

PATOČKA, J. 2005, Introducción a la fenomenología, Barcelona: Herder.

PAтоČKa, J. 2007, Libertad y sacrificio, Salamanca: Sígueme.

PatočKa, J. 20i 6, Le monde naturel comme problème philosophique, París: Vrin.

Srubar, I. I992, "Phénoménologie asubjective, monde de la vie et humanisme", en E. Tassin y M. Richir (ed.), Jan Patočka: philosophie, phénoménologie, politique, Grenoble: Millon, 85-100. 